\title{
Characterization of 100 extended major histocompatibility complex haplotypes in Indonesian cynomolgus macaques
}

\author{
Cecilia G. Shortreed ${ }^{1}$ (D) $\cdot$ Roger W. Wiseman ${ }^{1,2}$ (D) Julie A. Karl ${ }^{1}$ (D) - Hailey E. Bussan ${ }^{1}$ (D) $\cdot$ David A. Baker $^{1}$ (D)

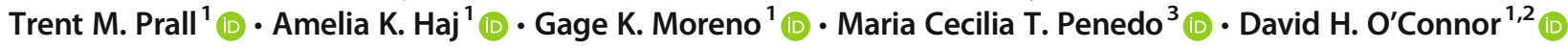

Received: 16 December 2019 / Accepted: 4 February 2020 /Published online: 29 February 2020

(C) Springer-Verlag GmbH Germany, part of Springer Nature 2020

\begin{abstract}
Many medical advancements - including improvements to anti-rejection therapies in transplantation and vaccine developmentrely on preclinical studies conducted in cynomolgus macaques (Macaca fascicularis). Major histocompatibility complex (MHC) class I and class II genes of cynomolgus macaques are orthologous to human leukocyte antigen complex (HLA) class I and class II genes, respectively. Both encode cell-surface proteins involved in cell recognition and rejection of non-host tissues. MHC class I and class II genes are highly polymorphic, so comprehensive genotyping requires the development of complete databases of allelic variants. Our group used PacBio circular consensus sequencing of full-length cDNA amplicons to characterize MHC class I and class II transcript sequences for a cohort of 293 Indonesian cynomolgus macaques (ICM) in a large, pedigreed breeding colony. These studies allowed us to expand the existing database of Macaca fascicularis (Mafa) alleles by identifying an additional $141 \mathrm{MHC}$ class I and 61 class II transcript sequences. In addition, we defined co-segregating combinations of allelic variants as regional haplotypes for 70 Mafa-A, 78 Mafa-B, and 45 Mafa-DRB gene clusters. Finally, we defined class I and class II transcripts that are associated with 100 extended MHC haplotypes in this breeding colony by combining our genotyping analyses with short tandem repeat (STR) patterns across the MHC region. Our sequencing analyses and haplotype definitions improve the utility of these ICM for transplantation studies as well as infectious disease and vaccine research.
\end{abstract}

Keywords Major histocompatibility complex $\cdot$ Macaca fascicularis $\cdot$ Short tandem repeat $\cdot$ Haplotype $\cdot$ Transplantation

\section{Introduction}

The highly polymorphic genes in the major histocompatibility complex (MHC) region are most notably involved in antigen presentation and recognition. In humans, the classical class I region contains three genes: $H L A-A, H L A-B$, and $H L A-C$. In macaques, there are only $M H C-A$ and $M H C-B$ orthologues,

Electronic supplementary material The online version of this article (https://doi.org/10.1007/s00251-020-01159-5) contains supplementary material, which is available to authorized users.

David H. O'Connor

dhoconno@wisc.edu

1 Department of Pathology and Laboratory Medicine, University of Wisconsin-Madison, Madison, WI 53711, USA

2 Wisconsin National Primate Research Center, University of Wisconsin-Madison, Madison, WI 53715, USA

3 Veterinary Genetics Laboratory, University of California-Davis, Davis, CA 95616, USA though there have been complex duplication events within this region, leading to MHC-A and MHC-B haplotypes with copy number variations that encode various combinations of major and minor transcripts as well as multiple pseudogenes (DazaVamenta et al. 2004; Fukami-Kobayashi et al. 2005; Watanabe et al. 2007). The class II region includes six distinct loci, which are the same in humans and macaques: $D R A, D R B$, $D Q A 1, D Q B 1, D P A 1$, and DPB1 (Shiina et al. 2017). Because macaques are commonly used as models for infectious disease, vaccine, and transplant studies, an emphasis has been placed on characterizing their MHC polymorphisms (Wiseman et al. 2013; Shiina and Blancher 2019).

Researchers using nonhuman primate (NHP) transplantation models need to control for differences in the MHC genotypes of donor and recipient tissues and often will vary degrees of disparity when testing tolerance therapies (Burwitz et al. 2017; Kean et al. 2012; Shiina and Blancher 2019). The National Institutes of Health (NIH) has recognized the need for and importance of transplant research conducted in NHP models since many immunomodulatory strategies that 
promote tolerance in rodent models have failed to translate successfully to humans (Knechtle et al. 2019). This led to the creation of the Nonhuman Primate Transplantation Tolerance Cooperative Study Group, whose goals include the development of novel regimens for immune tolerance induction, as well as understanding the mechanisms responsible for induction, maintenance, and/or loss of tolerance in NHP models of kidney, pancreatic islet, heart, and lung transplantation. In support of these studies, the NIH has established several breeding colonies in order to provide Indian-origin rhesus macaques, Mauritian-origin cynomolgus macaques (MCM), and Indonesian-origin cynomolgus macaques (ICM) to NHP transplant researchers. The MCM population displays extremely restricted MHC diversity with only seven ancestral MHC haplotypes (Wiseman et al. 2013). This population appears to have originated from a very small number of founding individuals who were introduced to Mauritius in the early 1500s (Lawler et al. 1995; Tosi and Coke 2007). While this restricted genetic diversity of the MCM population makes them extremely valuable for many types of biomedical research, it can be a disadvantage for transplant researchers whose objective is to maximize the amount of MHC disparity between donor and recipient tissues. In contrast, the ICM population displays extensive MHC diversity (Otting et al. 2012) which makes them an ideal NHP model for studies designed to evaluate the preclinical safety and efficacy of immune tolerance induction regimens that may be translated to clinical transplantation.

A number of investigators have used ICM (Ezzelarab et al. 2016; Zhang et al. 2015) as well as cynomolgus macaques from various other geographic origins (Kato et al. 2017; Matsunami et al. 2019; Shiina and Blancher 2019) for transplantation studies. For instance, ICM were used in a study to investigate $\mathrm{T}$ cell and alloantibody responses with purposely mismatched donor and recipient pairs (Ezzelarab et al. 2016). Another study (Morizane et al. 2017) utilizing a Filipino cynomolgus macaque model showed that when donor and recipient are matched for MHC genotypes, there are improved outcomes with neural cell grafts. Additionally, they observed inflammation in mismatched donor-recipient pairs. This indicates that the ability to accurately and efficiently characterize MHC genetics of model species like ICM is and will remain a necessity (Shiina and Blancher 2019).

Prior to this study, several reports have characterized ICM MHC sequence variants. In 2008, 48 novel MHC class I sequences were documented in 42 animals by Sanger sequencing of cDNA clones (Pendley et al. 2008). Likewise, Kita et al. (2009) surveyed 27 cynomolgus macaques of Indonesian descent and identified 34 novel Mafa-A sequences. Another study in 2011 (Creager et al. 2011) performed Sanger sequencing of MHC class II cDNA clones from a dozen unrelated ICM and identified 58 new transcript sequences. In the most comprehensive MHC genotyping analysis of ICM to date (Otting et al. 2012), Otting and colleagues characterized the class I and class II alleles that are associated with $32 \mathrm{ex}-$ tended MHC haplotypes in 120 ICM from a pedigreed breeding colony at the Biomedical Primate Research Centre (BPRC) in the Netherlands. More recently, these investigators evaluated MHC class II sequences in 79 ICM housed at the same colony that we examined in the present study (Otting et al. 2017). They identified 22 novel and extended 10 partial $M a f a-D Q$ and Mafa-DP sequences. Despite these previous studies characterizing ICM MHC sequence variants, we hypothesized that many additional MHC sequences remained to be characterized in this NIH-sponsored ICM breeding colony.

Several years ago, our group introduced the use of Pacific Biosciences (PacBio) single-molecule real-time sequencing to determine full-length MHC class I transcript sequences (Westbrook et al. 2015). Rapid improvements in PacBio circular consensus sequencing technology have made it possible to generate highly accurate sequences of cDNA amplicons from MHC class I and class II transcripts that span complete open reading frames of approximately $1100 \mathrm{bp}$ and $800 \mathrm{bp}$, respectively (Karl et al. 2014, 2017). This sequencing approach has proven useful in investigations of several understudied NHP populations such as Vietnamese, Cambodian, and Cambodian/Indonesian mixed-origin cynomolgus macaques at Chinese breeding centers (Karl et al. 2017). In a similar study of pig-tailed macaques from multiple breeding centers, PacBio sequencing of MHC class I cDNA amplicons was used to define over 300 novel Mane sequences as well as 192 Mane-A and Mane-B regional haplotypes (Semler et al. 2018). Here, we have extended this PacBio circular consensus sequencing approach to full-length cDNA amplicons from MHC class II as well as class I transcripts.

In addition to PacBio sequencing, we made use of an extensive database of short tandem repeat (STR) data spanning the $5 \mathrm{Mb}$ MHC region that has been generated over multiple generations of this NIH-sponsored ICM breeding colony (Penedo et al. 2005; Larsen et al. 2010). This is analogous to the approach that Otting et al. (Otting et al. 2012) employed to characterize extended MHC haplotypes in the BPRC cynomolgus macaque breeding groups. Doxiadis and colleagues (Doxiadis et al. 2013) employed a similar experimental strategy combining STR data with Sanger sequencing results in order to characterize the class I and class II transcript content of 176 founder haplotypes in a large breeding colony of rhesus macaques at the BPRC. Likewise, a related approach with pyrosequencing was utilized to characterize a closed colony of sooty mangabeys (Cercocebus atys) at the Yerkes National Primate Research Center for which STR data was available (Heimbruch et al. 2015). This study yielded 121 novel MHC class I transcript sequences that were assigned to $22 \mathrm{MHC}$ haplotypes that included combinations of both Ceat-A and $C$ eat $-B$ transcripts. Here, we combine PacBio sequencing with MHC STR patterns to unambiguously assign specific Mafa 
class I and class II transcripts to the extended MHC haplotypes that are segregating in this pedigreed ICM population.

\section{Methods}

\section{Animals}

All animals evaluated in this study were members of the NIHsponsored breeding colony at Alpha Genesis Inc. in Yemassee, SC, USA. that houses a cohort of approximately 350 ICM. This colony was established in 2002 and supplemented with additional groups of breeders in 2005 and 2010. The effective number of founding individuals was 79 for this breeding population. At least 16 of these founders were born in Indonesia although the precise location of these births was unknown, and the remaining founders were reported by their distributors to be of Indonesian origin. Demographic information about the 293 individuals that were evaluated by sequencing in this study is provided in Supplemental Figure 1. Whole blood samples were obtained during routine health checks from this cohort for sequence analyses. These individuals spanned multiple generations which allowed us to use pedigree data to compare multiple offspring from common sires and dams. All animals were cared for according to the regulations and guidelines of the Institutional Care and Use Committee at Alpha Genesis Inc.

\section{STR haplotype patterns}

STR analyses were completed as described previously (Penedo et al. 2005; Larsen et al. 2010) to determine parentage and place individuals within the pedigree. Next, STR allele sizes for a panel of 11 STR loci spanning the extended MHC region (Fig. 1) were compared between full- and half-siblings versus their parents in order to identify shared STR patterns that define the ancestral MHC haplotypes in this colony. Based on this analysis, each animal was assigned a pair of MHC haplotype codes, e.g., MHC-MAFA-NIAID1-00001 and MHC-MAFA-NIAID1-00002. Supplemental Figure 2 provides a list of the STR allele patterns that are associated with each of the 100 extended haplotypes that were defined by PacBio sequencing in this study.

\section{RNA isolation, CDNA synthesis, and PCR amplification}

RNA was isolated from whole blood in PAXgene Blood RNA tubes (Qiagen, Venlo, Netherlands) with a Maxwell 16 instrument using Maxwell 16 LEV SimplyRNA Blood kits

Fig. 1 Relative location of STR loci versus MHC class I and class II genes investigated in this study within the full genomic MHC region on chromosome 4

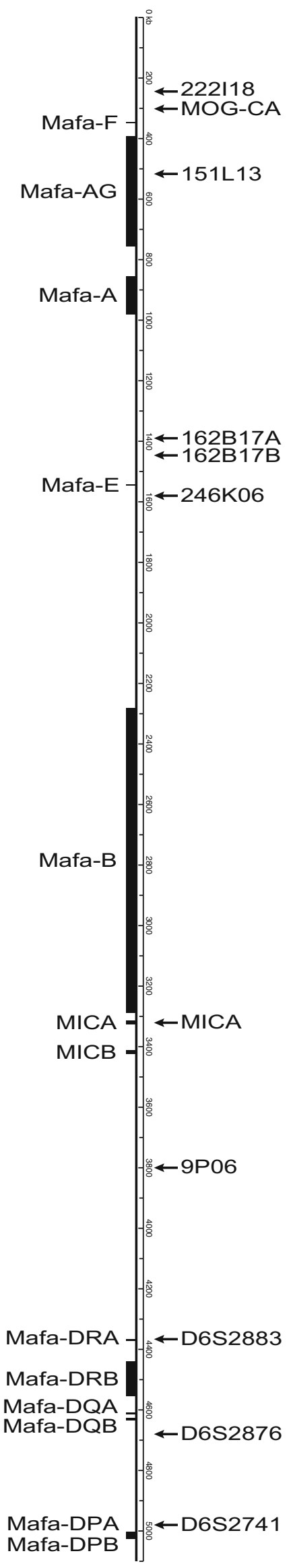


according to the manufacturer's protocol (Promega, Madison, WI, USA). Complementary DNA (cDNA) was then prepared from 50 ng RNA using a SuperScript III First-Strand Synthesis System for RT-PCR by Invitrogen (Carlsbad, CA, USA). The conditions for this reaction were: $65^{\circ} \mathrm{C}$ for $5 \mathrm{~min}$ to anneal oligo dT primers; $4{ }^{\circ} \mathrm{C}$ for $1 \mathrm{~min}, 50^{\circ} \mathrm{C}$ for $50 \mathrm{~min}$, and $85{ }^{\circ} \mathrm{C}$ for $5 \mathrm{~min}$ with Superscript enzyme; and finally, $37^{\circ} \mathrm{C}$ for 20 min after adding RNase $\mathrm{H}$. These cDNA templates were amplified through 23-30 cycles of PCR using Phusion High-Fidelity master mix (New England Biolabs, Ipswich, MA, USA). For MHC class I sequencing, we used a cocktail of two forward and three reverse barcoded primers (Supplemental Figure 3). These $50 \mu \mathrm{l}$ reactions included $1 \mu \mathrm{l}$ cDNA, $0.1 \mu \mathrm{M}$ primers, and Phusion High-Fidelity master mix. PCR reactions were run on an Applied Biosystems Thermal Cycler (ThermoFisher Scientific, Waltham, MA, USA) with reaction conditions of $98^{\circ} \mathrm{C}$ for $3 \mathrm{~min}$; 23 cycles of $98^{\circ} \mathrm{C}$ for $5 \mathrm{~s}, 60^{\circ} \mathrm{C}$ for $10 \mathrm{~s}$, and $72^{\circ} \mathrm{C}$ for $20 \mathrm{~s}$; followed by $72{ }^{\circ} \mathrm{C}$ for $5 \mathrm{~min}$. A similar process was used for MHC class II with a few distinctions (Karl et al. 2014). First, each of the class II loci required a separate PCR reaction and primers (Supplemental Figure 3). Additionally, we used 30 PCR cycles instead of 23, but with the same reaction conditions. All PCR products were monitored with FlashGels (Lonza, Basel, Switzerland) to confirm the anticipated length depending on the locus. PCR amplicons were then subjected to two rounds of cleanup with the AMPure XP PCR purification kit (Agencourt Bioscience Corporation, Beverly, MA, USA) in a 0.7:1 ratio of beads to PCR sample. Purified amplicons were quantified using Qubit High Sensitivity kits (ThermoFisher Scientific, Waltham, MA, USA).

\section{PacBio library preparation and sequencing}

For class I, amplicons were normalized to equal concentrations of $10 \mathrm{ng} / \mu \mathrm{l}$ in pools of 32-48 samples per PacBio library. For class II, we pooled 32-48 samples by loci, and each pool was quantified with Qubit High Sensitivity kits. These individual subpools were then combined into a final pool with $500 \mathrm{ng}$ DNA total in the ratio 3 DRB: 1 DQA: $1 D Q B: 1$ $D P A: 1 D P B$. Prior to sequencing, SMRTbell adaptors, which form hairpins on the ends of the amplicons, were ligated according to the manufacturer's protocol. Sequencing was completed on a PacBio Sequel instrument (PacBio, Menlo Park, CA, USA) at the University of Wisconsin-Madison Biotechnology Center.

\section{PacBio circular consensus sequence analysis}

Raw sequence data was processed using the SMRT Link v6.0.0 command-line toolset (https://www.pacb.com/ support/software-downloads/). Briefly, SMRT Link Dataset was run on raw sequencing data to produce a processed
XML file. The resulting XML file was converted into BAM format containing circular consensus sequences (CCS) using the SMRT Link CCS tool with the minimum and maximum length parameters set to 1000 and 1500 for MHC class I and 700 and 1000 for MHC class II. BAM files were then converted to fastq format using the SMRT Link BAM2FASTQ tool. Fastq files were demultiplexed by barcodes using custom python code (https://github.com/dholab/Shortreed-et-alSupplemental-Code). These demultiplexed fastq files are available for download (https://go.wisc.edu/5sq9i9). Long Amplicon Analysis (LAA) was run on each demultiplexed fastq file. For both MHC class I and II, the Max_Clustering Reads parameter was set to 5000 and Max_reads parameter was set to 20,000 .

Resulting amplicon sequences were mapped against the most recent library as of each sequencing run of known fulllength Mafa MHC sequences in the NHP Immuno Polymorphism Database (IPD-MHC) using bbmap (http:// sourceforge.net/projects/bbmap/) in semiperfect mode. Fulllength LAA sequences that matched with perfect identity were removed from further analysis, as these represented known alleles. The remaining LAA sequences were mapped to a library of known partial Mafa MHC sequences using bbmap in semiperfect mode. Sequences that perfectly matched a partial sequence in the database were marked as putative extensions. Sequences that differed by one or more single nucleotide variants were marked as putative novel alleles. All of these putative novel and extended sequences were given temporary names and added to the database for the remainder of data processing. Next, reads for each animal were mapped against the database containing putative novels, putative extensions, and known sequences.

\section{DNA isolation, multiplex PCR, and Illumina MiSeq analysis}

Genomic DNAs were isolated from whole blood EDTA samples with a Maxwell 16 instrument using Maxwell 16 LEV Blood DNA kits according to the manufacturer's protocol (Promega, Madison, WI, USA). These genomic DNAs were used as templates for PCR with a panel of primers that flank the highly polymorphic peptide binding domains encoded by exon 2 of class I (Mafa-A, Mafa-B, Mafa-I, Mafa-E) and class II (Mafa-DRB, Mafa-DQA, Mafa-DQB, Mafa-DPA, and $M a f a-D P B)$ loci. These PCR products were generated with a Fluidigm Access Array 48.48 (Fluidigm, San Francisco, CA, USA) which allows us to multiplex all reactions in a single experiment as described previously (Karl et al. 2014, 2017). After cleanup and pooling, these amplicons were sequenced on an Illumina MiSeq instrument (Illumina, San Diego, CA, USA). The resulting Illumina sequence reads were mapped against a custom reference database of Mafa class I and class II sequences as previously described (Caskey et al. 2019). 


\section{Allele validation and haplotype analysis}

Validation of novel and extended sequences was a multi-step process. First, we used Geneious (Biomatters, Auckland, New Zealand) software to visualize and confirm that the sequences had the expected start and stop amino acid sequences and that there were not any significant gaps or insertions such that the length was within the expected range for each locus. Next, we considered the number of PacBio CCS reads that supported a particular sequence relative to other reads in the same animal and compared across related animals. A potential novel allele that was supported by a minimum of three identical CCS reads in one or more animals was considered valid if there were not alleles of the same lineage with better read support within the same animal(s). These criteria prevent mischaracterization of PCR artifacts and sequencing errors, such as chimeras (Caskey et al. 2019; Fichot and Norman 2013), as valid new MHC sequences.

Mafa class I and class II transcripts that are associated with extended MHC haplotypes in this breeding colony were assigned based on their identification in multiple individuals that share a specific MHC-MAFA-NIAID1 STR pattern. In a few cases where PacBio class I and/or class II sequencing results were only available for a single individual representing one of the less frequent MHC haplotypes, transcripts that remained after those associated with a more common, shared haplotype had been identified were inferred to segregate with these rare MHC haplotypes. The Mafa-A, Mafa-B, and Mafa$D R B$ gene clusters are physically linked with a strong tendency to travel together as regional haplotypes (Karl et al. 2017). Since each of these gene clusters is separated by approximately $1 \mathrm{Mb}$ on chromosome 4, however, an occasional recombination event may occur that breaks the linkage between these haplotype blocks. To provide a concise description of each of these allele combinations, we developed a series of abbreviated Mafa-A, Mafa-B, and Mafa-DRB haplotype designations (Karl et al. 2017). The specific Mafa transcript sequences that we have defined for each of these regional haplotypes in the Alpha Genesis breeding colony are summarized in Supplemental Figures 4-6.

\section{Results and discussion}

\section{Novel Mafa transcripts and extensions of partial Mafa sequences}

In the initial phase of this study, we performed MHC class I allele discovery by PacBio circular consensus sequencing of full-length cDNA amplicons from a total of 293 ICM in this breeding colony. PacBio sequencing yielded an average of $1668 \mathrm{MHC}$ class I reads per animal that were either identical to known Mafa alleles, extensions of previously described partial Mafa sequences, or validated as novel Mafa allelic variants. These novel Mafa transcript sequences differed by one or more synonymous or nonsynonymous nucleotide changes compared with previously reported Mafa sequences available in IPD-MHC (Maccari et al. 2017). In total, we identified 141 class I sequences in this study (Table 1, Supplemental Figure 7); 90 of these transcripts represented novel sequences and there were 27 Mafa-A, 53 Mafa-B, and $10 \mathrm{Mafa}-\mathrm{I}$ allelic variants. These new Mafa class I sequences have been deposited in the IPD-MHC Non-Human Primate Database (https://www.ebi.ac.uk/ipd/mhc/group/NHP) (de Groot et al. 2019).

For characterization of MHC class II sequences, we adopted a targeted allele discovery strategy that made use of STR profiles for the MHC region that had been used to define extended MHC haplotypes in this ICM breeding colony. Based on knowledge of these STR patterns, we selected 76 representative animals that carried a total of 100 distinct ancestral MHC haplotypes. PacBio sequencing was performed with full-length cDNA amplicons for MHC class II loci and yielded a total of $3857 \mathrm{MHC}$ class II reads per animal. We identified a total of 61 additional full-length class II sequences. As summarized in Table 1, 39 of these class II sequences were novel and they included 17 Mafa-DRB, 12 Mafa-DQA1, 4 Mafa-DQB1, 3 Mafa-DPA1, and 3 Mafa$D P B 1$ allelic variants that have also been deposited in IPDMHC (Table 1).

\section{Defining transcripts associated with regional and extended MHC haplotypes}

After characterizing new class I and class II sequences with PacBio sequencing, we turned our efforts to defining the transcripts that are associated with the extended MHC haplotypes that are currently segregating in the Alpha Genesis breeding colony. Each of these extended MHC haplotypes has been defined by distinct patterns of allele sizes for a panel of eleven STR markers that span the $5 \mathrm{Mb}$ MHC genomic region

Table 1 Summary of full-leng 293 animals by locus

\begin{tabular}{lllll}
\hline Gene & Known & Novel & Extension & Total \\
\hline Mafa-A & 73 & 27 & 22 & 122 \\
Mafa-B & 166 & 53 & 26 & 245 \\
Mafa-I & 23 & 10 & 3 & 36 \\
Mafa-DRB & 47 & 17 & 17 & 81 \\
Mafa-DQA & 22 & 12 & 1 & 35 \\
Mafa-DQB & 29 & 4 & 1 & 34 \\
Mafa-DPA & 21 & 3 & 1 & 25 \\
Mafa-DPB & 18 & 3 & 2 & 23 \\
Total & 399 & 129 & 73 & 601 \\
\hline
\end{tabular}


(Supplemental Figure 2) (Penedo et al. 2005; Larsen et al. 2010). As illustrated in Fig. 2, each extended MHC haplotype in cynomolgus macaques encodes multiple Mafa-A, Mafa- $B$, and $M a f a-D R B$ transcripts. In addition, there is considerable copy number variation between haplotypes as well as a wide range of steady-state RNA levels in whole blood for Mafa-A and $M a f a-B$ transcripts from different loci. In order to describe the complex, high-resolution Mafa genotypes associated with each of the extended MHC haplotypes, we developed an abbreviated, regional haplotype nomenclature system for the Mafa-A, Mafa-B, and Mafa-DRB gene clusters that is similar to $\mathrm{MHC}$ allele nomenclature (Fig. 2). Each of these regional haplotype designations begins with the species name (Mafa) and a "diagnostic" allele lineage for a major transcript that is expressed at high steady-state levels, e.g. A018. Regional haplotypes that differ in their combinations of major transcripts are distinguished by a "." delimiter followed by two digits in ascending order of their identification in various cynomolgus macaque populations. A final "." delimiter separates closely related haplotypes that share the same major transcript lineages but differ due to nonsynonymous and/or synonymous allelic variants. For example, the regional Mafa-A018.01.05 haplotype illustrated in Fig. 2 includes major Mafa$A 1 * 018: 05: 02$ and minor Mafa-A2*05:66 transcripts and it represents the fifth combination of allelic variants noted to date. Using this abbreviated haplotype system, the extended MHC haplotypes defined by the MHC-MAFA-NIAID1-

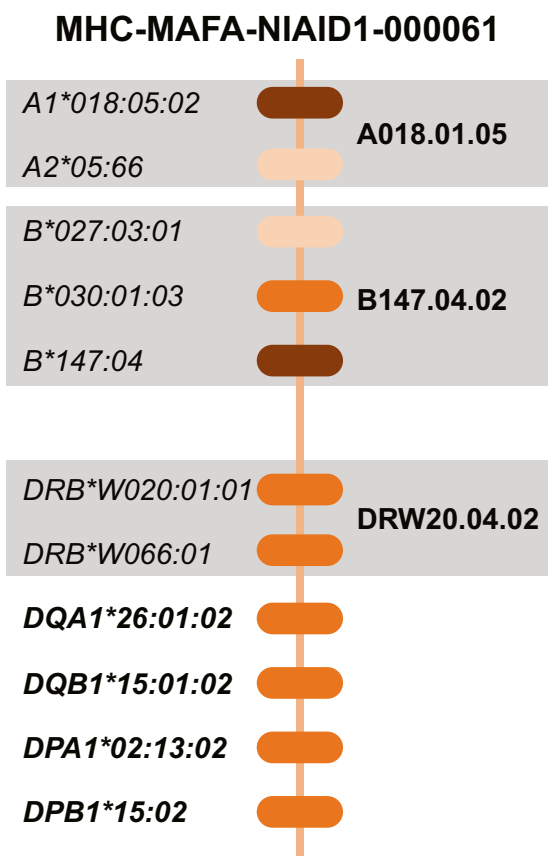

Fig. 2 An example of an extended MHC haplotype defined by the MHCMAFA-NIAID1-000061 STR pattern. For Mafa-A, Mafa-B, and Mafa$D R \mathrm{~B}$, multiple transcripts with a wide range of steady-state RNA levels as indicated by the intensity of the color of the locus bubble, together make up the regional haplotype in bold. For the remaining class II loci, each gene is indicated by a single transcript in bold font
000061 STR pattern can be described by the following string: A018.01.05|B147.04.02|DRBW020.04.02|DQA26_01_01| DQB15_01_02|DPA02_13_02|DPB15_02.

Genotyping results for a representative group of four progeny from sire CX7K is presented in Fig. 3 to illustrate how PacBio sequencing data is used to define the Mafa transcripts that are associated with extended MHC haplotypes. In this example, each of the offspring inherited the same paternal MHC haplotype that is defined by the MHC-MAFANIAID1-000048 STR pattern. The values in the body of Fig. 3 indicate the PacBio sequence read support for each of the class I and class II transcripts that were identified in each animal and color coding denotes the haplotype for each sequence. Transcripts highlighted in yellow are shared by all four of these offspring and thus are assigned to the paternal haplotype that was inherited from the CX7K sire. The Mafa-B gene cluster of this extended haplotype includes a diagnostic major $M a f a-B^{*} 028: 06$ transcript as well as six additional $M a f a-B$ transcripts with a range of steady-state RNA levels. To simplify communicating these genotyping results we abbreviate this combination of Mafa-B loci as the MafaB028.07.01 regional haplotype. In the same way, the transcripts that are unique in each of these progeny are inferred to be associated with their maternal haplotypes (Fig. 3). For instance, the combination of Mafa- $B * 147: 04$, Mafa$B * 030: 01: 03$, and $M a f a-B * 027: 03: 01$ transcripts expressed by $\mathrm{H} 592$ are designated as the Mafa-B147.04.02 regional haplotype. This Mafa-B haplotype is one building block of the MHC-MAFA-NIAID1-000061 extended haplotype that was inherited from dam CX95.

By iterating this process with PacBio genotyping results from groups of related animals that share STR patterns from common ancestors, we defined the class I and class II transcripts that are associated with 100 extended MHC haplotypes in this breeding colony as summarized in Table 2 . Supplemental Figures 4-6 provide lists of the Mafa-A, $M a f a-B$, and $M a f a-D R B$ transcripts that are associated with each of the abbreviated, regional Mafa haplotype designations displayed in Table 2. Complete PacBio read support per transcript is available for all animals sequenced in this study in Supplemental Figure 8. In a few cases where PacBio read support was low, these results were augmented with lineagelevel MiSeq genotyping results with exon 2 genomic DNA amplicons as shown in Supplemental Figure 9 (Karl et al. 2017).

As a result of these efforts, we identified 70 distinct combinations of Mafa-A transcripts (Supplemental Figure 4) and 78 distinct combinations of Mafa- $B$ transcripts (Supplemental Figure 5). At least 45 combinations of Mafa-DRB transcripts were also observed in this cohort (Supplemental Figure 6). Since $M a f a-D Q$ and Mafa-DP haplotypes each only include single genes for the alpha and beta chains, the individual alleles for these four loci are listed for each extended MHC 


\begin{tabular}{|c|c|c|c|c|c|c|c|c|c|}
\hline Animal ID & H592 & H31C & H589 & J825 & Animal ID & H592 & H31C & H589 & J825 \\
\hline Sire ID & CX7K & CX7K & CX7K & CX7K & reads mapped & 904 & 800 & 870 & 2273 \\
\hline Dam ID & CX95 & $\mathrm{CX} 97$ & DK7R & CX4R & STR Profile 1 & 48 & 48 & 48 & 48 \\
\hline reads mapped & 1431 & 1408 & 1094 & 2435 & STR Profile 2 & 61 & 49 & 35 & 22 \\
\hline STR Profile 1 & 48 & 48 & 48 & 48 & DRB Haplotype 1 & DRW03.01.02 & DRW03.01.02 & DRW03.01.02 & DRW03.01.02 \\
\hline STR Profile 2 & 61 & 49 & 35 & 22 & DRB Haplotype 2 & DRW20.04.02 & DR110.01.02 & DRW01.04.01 & DRW04.01.02 \\
\hline A Haplotype 1 & A003.01.01 & A003.01.01 & $\mathrm{A} 003.01 .01$ & A003.01.01 & DQA Haplotype 1 & 24:02:04 & 24:02:04 & 24:02:04 & 24:02:04 \\
\hline A Haplotype 2 & A018.01.05 & A053.01.01 & A058.01.03 & A088.01.02 & DQA Haplotype 2 & $26: 01: 02$ & $05: 16$ & 01:11 & 01:15:02 \\
\hline B Haplotype 1 & B028.07.01 & B028.07.01 & B028.07.01 & B028.07.01 & DQB Haplotype 1 & $18: 08$ & $18: 08$ & $18: 08$ & $18: 08$ \\
\hline B Haplotype 2 & B147.04.02 & B015.07.01 & B083.02.02 & B028.06.01 & DQB Haplotype 2 & $15: 01: 02$ & $17: 11$ & 06:07:01 & $06: 43$ \\
\hline Mafa-A & & & & & DPA Haplotype 1 & 09:02 & 09:02 & 09:02 & 09:02 \\
\hline$A 1^{*} 003: 01$ & 72 & 38 & 56 & 109 & DPA Haplotype 2 & 02:13:02 & $04: 02$ & $02: 11$ & 02:05 \\
\hline$A 1^{*} 018: 05: 02$ & 307 & & & & DPB Haplotype 1 & $17: 01: 02$ & $17: 01: 02$ & 17:01:02 & $17: 01: 02$ \\
\hline$A 1^{*} 053: 01$ & & 137 & & & DPB Haplotype 2 & 15:02 & 02:02 & 10:01 & $15: 03$ \\
\hline$A 1^{*} 058: 01$ & & & 221 & & Mafa-DRB & & & & \\
\hline$A 1^{*} 088: 01$ & & & & 559 & $D R B 1 * 10: 01$ & & 50 & & \\
\hline$A 1^{*} 086: 01: 01$ & & & & 31 & $D R B^{*} W 001: 07$ & & & 17 & \\
\hline$A 2^{*} 05: 60$ & & 1 & & & $D R B^{*} W 003: 03: 01$ & 6 & 35 & 19 & 261 \\
\hline$A 2^{*} 05: 65$ & & & & 51 & $D R B^{\star} W 003: 06$ & & & 8 & \\
\hline$A 2^{\star} 05: 66$ & 2 & & & & $D R B^{*} W 004: 07$ & & 19 & & \\
\hline$A 4^{*} 14: 01$ & & 9 & & & $D R B^{*} W 007: 02$ & 7 & 77 & 32 & 684 \\
\hline Mafa-B Major & & & & & $D R B^{*} W 020: 01: 01$ & 3 & & & \\
\hline$B^{*} 015: 10$ & & 148 & & & $D R B^{*} W 025: 04$ & & & & 1246 \\
\hline$B^{\star} 021: 01$ & 61 & 28 & 14 & 71 & $D R B^{*} W 026: 02: 01$ & & & 11 & \\
\hline$B^{*} 027: 03: 01$ & 8 & & & & $D R B^{*} W 066: 01$ & 10 & & & \\
\hline$B^{*} 028: 03$ & & & & 116 & Mafa-DQA1 & & & & \\
\hline$B^{*} 028: 06$ & 345 & 478 & 323 & 635 & $D Q A 1^{*} 01: 11$ & & & 168 & \\
\hline$B^{*} 030: 01: 03$ & 69 & & & & $D Q A 1^{*} 01: 15: 02$ & & & & 610 \\
\hline$B^{*} 030: 04$ & 54 & 64 & 83 & 129 & $D Q A 1^{*} 05: 16$ & & 160 & & \\
\hline$B^{*} 041: 02$ & & & 47 & & $D Q A 1^{*} 24: 02: 04$ & 301 & 362 & 257 & 718 \\
\hline$B^{*} 041: 04$ & 53 & 47 & 44 & 38 & $D Q A 1^{*} 26: 01: 02$ & 218 & & & \\
\hline$B^{*} 068: 02$ & & & & 218 & Mafa-DQB1 & & & & \\
\hline$B^{*} 068: 13$ & & 102 & & & $D Q B 1^{*} 06: 07: 01$ & & & 574 & \\
\hline$B^{*} 083: 02$ & 166 & 263 & 110 & 204 & $D Q B 1^{*} 06: 43$ & & & & 877 \\
\hline$B^{*} 083: 03$ & & & 125 & & $D Q B 1 * 15: 01: 02$ & 68 & & & \\
\hline$B^{*} 117: 05$ & 89 & 47 & 60 & 189 & $D Q B 1 * 17: 11$ & & 293 & & \\
\hline$B^{*} 124: 02$ & & & & 12 & $D Q B 1 * 18: 08$ & 37 & 281 & 509 & 520 \\
\hline$B^{*} 147: 04$ & 161 & & & & Mafa-DPA1 & & & & \\
\hline$B^{*} 151: 01$ & & & & 24 & $D P A 1^{*} 02: 05$ & & & & 304 \\
\hline \multirow[t]{10}{*}{$B^{*} 151: 03$} & 42 & 39 & 10 & 23 & $D P A 1^{*} 02: 11$ & & & 393 & \\
\hline & & & & & $D P A 1^{*} 02: 13: 02$ & 442 & & & \\
\hline & & & & & $D P A 1^{*} 04: 02$ & & 282 & & \\
\hline & & & & & $D P A 1^{*} 09: 02$ & 51 & 138 & 46 & 334 \\
\hline & & & & & Mafa-DPB1 & & & & \\
\hline & & & & & $D P B 1^{*} 02: 02$ & & 380 & & \\
\hline & & & & & $D P B 1^{*} 10: 01$ & & & 431 & \\
\hline & & & & & $D P B 1^{*} 15: 02$ & 408 & & & \\
\hline & & & & & $D P B 1^{*} 15: 03$ & & & & 1630 \\
\hline & & & & & $D P B 1^{*} 17: 01: 02$ & 3 & [inferred] & [inferred] & 5 \\
\hline
\end{tabular}

Fig. 3 PacBio sequencing results for four of the 293 macaques in this study. MHC class I results are shown on the left and class II data is on the right side. For each macaque, we list the animal ID, sire ID, dam ID, and number reads mapped with PacBio sequencing. Only major Mafa-B reads are listed for illustrative purposes, but complete data including minor transcripts can be found in Supplemental Figure 8. Each of these animals shares a common sire and inherited the paternal haplotype containing the MHC-MAFA-NIAID1-000048 STR pattern (yellow). Each of the progeny expresses a series of class I and class II transcripts in common (yellow) that are represented by the number of identical PacBio sequences reads that were detected in each animal. These co-

haplotype in Table 2. These results indicate that there are 45 distinct combinations of Mafa-DQA1/Mafa-DQB1 alleles and 38 different pairs of Mafa-DPA1/Mafa-DPB1 alleles. Many of these Mafa-DQ and Mafa-DP haplotypes confirm previous observations for individuals from this and other breeding colonies (Otting et al. 2017).

The majority of the regional Mafa-A, Mafa-B, and MafaDRB haplotypes detected in this breeding colony are restricted to one or two extended MHC haplotypes (Supplemental segregating transcripts are used to define the abbreviated regional haplotypes listed below the STR profiles. The remaining transcripts expressed by each animal are highlighted in a different color and inferred to segregate as the maternal haplotype inherited from their respective dams. Diagonally shaded boxes indicate that a transcript such as Mafa$B * 030: 04$ is included on both the paternal and maternal extended MHC haplotypes. If PacBio read support is low, but a sequence is observed in related animals and/or MiSeq data, it is noted as inferred, e.g., Mafa$D P A 1 * 17: 01: 02$ for the extended haplotype defined by the shared MHC-MAFA-NIAID1-000048 STR pattern

Figures 4-6). This observation is consistent with a previous study by Otting and colleagues that characterized 32 multilocus MHC haplotypes for pedigreed cynomolgus macaque breeding groups at the Biomedical Primate Research Center (BPRC) in the Netherlands (Otting et al. 2012). Several Mafa$\mathrm{A}$ and Mafa-B regional haplotypes are shared by multiple extended haplotypes however and do appear to be somewhat enriched in the Alpha Genesis breeding colony. For example, the Mafa-A004.01.02, Mafa-A010.01.05, and Mafa- 
B013.08.01 haplotypes are each associated with six extended MHC haplotypes (Supplemental Figures 4 and 5). These extended MHC haplotypes do not appear to result from simple recombination events in the class I region that arose in recent ancestors of this breeding colony. As illustrated in Fig. 4, the STR patterns flanking the Mafa-A004.01.02 haplotypes provide evidence of a conserved genomic region that is marked by three to six common telomeric and centromeric STR alleles in four extended MHC haplotypes, but each of these MafaA004.01.02 haplotype blocks is linked to distinct Mafa-B and class II haplotypes. As illustrated in Fig. 1, the first three STRs (222I18, MOG-CA and 151L13) reside approximately 0.3$0.6-\mathrm{Mb}$ telomeric to the $M a f a-A$ gene cluster and the next three STRs (162B17A, 162B17B, and 246K06) are localized a comparable distance from the centromere (Daza-Vamenta et al. 2004; Kean et al. 2012) where they flank the Mafa-E genes. Interestingly, the major Mafa-Al*004:03 transcript that is included as part of this Mafa-A004.01.02 haplotype was originally identified as the most common $M a f a-A l$ sequence identified in a cohort of ICM (Kita et al. 2009). In contrast, the STR patterns flanking the regional Mafa-A010.01.05 haplotypes are essentially completely distinct (Fig. 4), suggesting that these six extended MHC haplotypes are truly ancient configurations. Unlike the extended cynomolgus macaque MHC haplotypes described here, the Indian-origin rhesus macaque population is characterized by a relatively limited number of Mamu-A, Mamu-B, and Mamu-DRB regional haplotype blocks that have been shuffled by recombination to generate extended MHC haplotype diversity (Doxiadis et al. 2013; Karl et al. 2013; Wiseman et al. 2013).

Among the 293 macaques that were evaluated by deep sequencing in this study (Supplemental Figure 1), there was only direct evidence for a single recombination event with the core $\mathrm{MHC}$ region. Animal $\mathrm{H} 82 \mathrm{H}$ inherited the recombinant MHC-MAFA-NIAID1-000138 haplotype from sire CM9P. This recombinant haplotype has a breakpoint in the class III region between the 9P06 marker of MHC-MAFA-NIAID1000001 and the D6S2883 marker for MHC-MAFANIAID1-000005 (Fig. 1, Supplemental Figure 2). As expected based on the location of this breakpoint for MHC-MAFANIAID1-000138, deep sequencing results demonstrated that it includes class I genes for the A018.01.03/B018.02.01 haplotypes from MHC-MAFA-NIAID1-000001 together with the DRW33.01/DQA24g1/DQB18:08/DPA02g3/DPB15g3 class II genes from the MHC-MAFA-NIAID1-000005 haplotype (Table 2, Supplemental Figures 8 and 9). This cohort included a total of 567 meioses that were informative for the detection of recombination within the core MHC region between the $M a f a-F$ and $M a f a-D P B$ genes. Therefore, this single recombination event yields an observed recombination rate per generation within the MHC of $0.2 \%$. In a previous study, Aarnink and coworkers observed three MHC recombination events out of 282 informative meiosis (1.06\%) in a captive breeding population of Mauritian cynomolgus macaques (Aarnink et al.

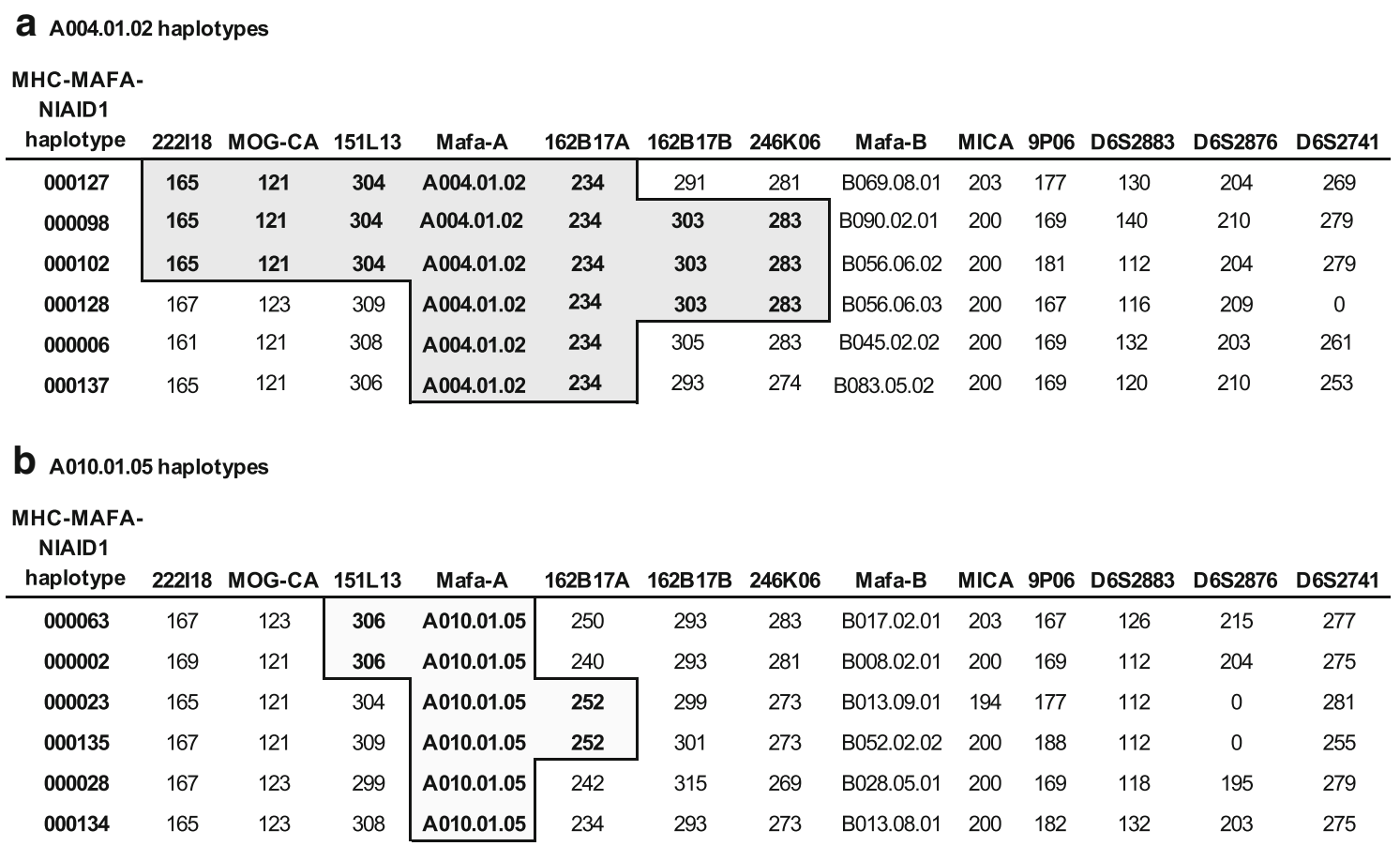

Fig. 4 STR patterns for extended MHC haplotypes that share MafaA004.01.02 or Mafa-A010.01.05 haplotypes. STR loci are displayed from telomere (left) to centromere (right) and STR allele sizes that define each extended haplotype are listed. Shading and boldface highlights the STR alleles that are shared between multiple extended haplotypes that include Mafa-A004.01.02 (a) or Mafa-A010.01.05 (b) haplotypes 
Table 2 Mafa haplotype definitions for 100 extended MHC haplotypes defined by MHC-MAFA-NIAID1 STR patterns. STR allele sizes for each extended MHC haplotype are listed in Supplemental Figure 2. The number of each haplotype observed (\# Obs.) was inferred based on animals with STR patterns matching the 100 extended MHC haplotypes characterized in this study $(n=1146)$. Mafa class I and class II transcripts associated with each of the abbreviated Mafa-A, Mafa-B, and Mafa-DRB regional haplotypes are listed in Supplemental Figures 4 - 6. Individual $M a f a-D Q A 1, D Q B 1, D P A 1$, and $D P B 1$ alleles associated with each extended MHC haplotype are listed in the final four columns

\begin{tabular}{|c|c|c|c|c|c|c|c|c|}
\hline $\begin{array}{l}\text { MHC-MAFA- } \\
\text { NIAID1- }\end{array}$ & \# Obs. & Mafa-A & Mafa-B & Mafa-DRB & $\begin{array}{l}\text { Mafa- } \\
\text { DQA }\end{array}$ & $\begin{array}{l}\text { Mafa- } \\
\text { DQB }\end{array}$ & $\begin{array}{l}\text { Mafa- } \\
\text { DPA }\end{array}$ & $\begin{array}{l}\text { Mafa- } \\
\text { DPB }\end{array}$ \\
\hline 000005 & 124 & A007.01.03 & B008.02.02 & DRW33.01.01 & 24:02:01 & 18:08 & 02:13:02 & $15: 02$ \\
\hline 000002 & 62 & A010.01.05 & B008.02.01 & DR104.06.03 & 01:03:05 & $06: 12$ & 02:13:02 & $15: 02$ \\
\hline 000008 & 45 & A060.02.01 & B015.05.01 & DR103.02.02 & 01:24:01 & $06: 13: 01$ & 04:02 & 03:04:01 \\
\hline 000001 & 35 & A018.01.03 & B018.02.01 & DR103.01.02 & $24: 05$ & $18: 05$ & $02: 11$ & $10: 01$ \\
\hline 000010 & 35 & A022.01.06 & B147.03.01 & DR103.06.01 & 01:03:02 & $06: 18$ & 07:07 & 19:06:01 \\
\hline 000025 & 34 & A054.01.01 & B013.08.01 & DR401.02.01 & $01: 21$ & $06: 24: 02$ & 04:02 & 03:04:01 \\
\hline 000007 & 30 & A103.01.01 & B015.01.02 & DR103.20.01 & 01:03:02 & $06: 18$ & 04:02 & 03:04:01 \\
\hline 000006 & 29 & A004.01.02 & B045.02.02 & DR103.12.01 & 01:07:01 & $06: 14$ & 04:02 & 03:06 \\
\hline 000048 & 29 & A003.01.01 & B028.07.01 & DRW03.01.02 & 24:02:04 & 18:08 & 09:02 & 17:01:02 \\
\hline 000009 & 28 & A008.01.02 & B004.03.01 & DRW21.01.01 & $05: 10$ & 17:02:01 & 02:14:01 & 01:05 \\
\hline 000022 & 26 & A088.01.02 & В028.06.01 & DRW04.02.01 & 01:15:02 & $06: 43$ & 02:05 & $15: 03$ \\
\hline 000028 & 26 & A010.01.05 & B028.05.01 & DR103.18.01 & $24: 05$ & $18: 05$ & 02:13:02 & $15: 02$ \\
\hline 000132 & 25 & A089.01.03 & B056.04.01 & DR110.04.01 & 05:03:01 & $16: 01$ & 02:05 & $15: 03$ \\
\hline 000018 & 23 & A043.01.04 & В076.02.01 & DRW04.01.01 & 01:12 & $06: 14$ & 07:04:01 & $21: 02$ \\
\hline 000003 & 22 & A038.01.03 & B024.01.01 & DR103.06.01 & 01:03:02 & $06: 18$ & 07:01 & $21: 02$ \\
\hline 000019 & 21 & A007.01.03 & B002.01.02 & DR103.05.01 & 05:01:01 & $17: 03$ & $02: 18$ & 06:06:02 \\
\hline 000072 & 20 & A019.01.02 & B090.03.01 & DRW33.01.01 & $24: 04$ & $18: 05$ & 07:02 & $19: 03$ \\
\hline 000013 & 18 & A043.01.05 & B004.01.01 & DR103.06.01 & 01:03:05 & $06: 12$ & 02:13:02 & $15: 02$ \\
\hline 000035 & 17 & A058.01.03 & B083.02.02 & DRW01.04.01 & 01:11 & 06:07:01 & 02:15:01 & 10:01 \\
\hline 000037 & 15 & A068.01.01 & B008.02.01 & DRW05.01.01 & $24: 03$ & 18:01:02 & $02: 27$ & 01:01:01 \\
\hline 000117 & 15 & A019.01.01 & B028.01.04 & DR104.13.01 & $24: 07$ & $18: 28$ & 02:01 & $25: 03$ \\
\hline 000036 & 14 & A019.01.01 & B052.02.01 & DRW01.02.03 & 23:01:01 & $18: 31$ & 04:02 & 03:04:01 \\
\hline 000058 & 14 & A010.01.03 & B056.04.02 & DRW04.01.01 & 01:12 & $06: 14$ & 02:15:01 & 10:01 \\
\hline 000063 & 14 & A010.01.05 & B017.02.01 & DR103.05.01 & 05:01:01 & $17: 03$ & 02:09:02 & $15: 09$ \\
\hline 000004 & 13 & A101.01.01 & B016.01.02 & DRW04.01.01 & $01: 12$ & 06:08 & 02:15:01 & $10: 01$ \\
\hline 000031 & 12 & A054.01.02 & B069.07.01 & DRW04.01.01 & $01: 12$ & $06: 14$ & 02:09:02 & $15: 09$ \\
\hline 000043 & 12 & A088.01.01 & B184.01.03 & DRW01.04.01 & 01:11 & 06:07:01 & $02: 26$ & $25: 03$ \\
\hline 000032 & 14 & A019.02.01 & B090.01.01 & DRW21.02.01 & 23:01:01 & 18:04 & 11:01 & $16: 01$ \\
\hline 000061 & 11 & A018.01.05 & B147.04.02 & DRW20.04.02 & 26:01:02 & $15: 01: 02$ & 02:13:02 & $15: 02$ \\
\hline 000064 & 11 & A070.01.01 & B181.02.01 & DR103.06.01 & 01:03:02 & $06: 18$ & 07:07 & 19:06:01 \\
\hline 000130 & 11 & A060.01.03 & B101.02.01 & DR103.06.01 & 01:03:02 & $06: 18$ & 02:13:02 & $15: 02$ \\
\hline 000052 & 10 & A053.01.01 & B004.01.02 & DRW21.02.01 & 23:01:01 & $18: 04$ & 07:03 & 19:06:02 \\
\hline 000076 & 11 & A135.01.01 & B008.02.03 & DRW01.04.01 & 01:11 & 06:07:01 & $13: 03$ & 04:01 \\
\hline 000077 & 10 & A066.01.04 & B017.03.01 & DR104.05.02 & 01:06:01 & 06:11:02 & 09:02 & $17: 01: 02$ \\
\hline 000011 & 8 & A076.01.01 & В028.06.03 & DR107.02.01 & $24: 05$ & $18: 05$ & 04:02 & 03:04:03 \\
\hline 000024 & 9 & A043.01.07 & B045.02.01 & DR103.06.01 & 01:03:02 & $06: 18$ & 02:15:01 & $10: 01$ \\
\hline 000027 & 9 & A091.01.01 & B147.02.01 & DRW03.01.03 & $24: 02: 03$ & $18: 08$ & $02: 26$ & $25: 04$ \\
\hline 000030 & 9 & A070.01.01 & B013.08.01 & DRW21.02.01 & 23:01:01 & 18:04 & 09:02 & $17: 01: 02$ \\
\hline 000047 & 9 & A053.01.01 & B004.01.02 & DRW01.02.03 & $24: 03$ & $18: 04$ & 04:02 & 03:04:01 \\
\hline 000097 & 9 & A018.01.04 & B004.01.01 & DRW01.03.01 & 05:01:01 & $17: 03$ & 02:15:01 & 10:01 \\
\hline 000131 & 9 & A063.01.04 & B104.01.02 & DRW03.01.02 & 24:02:03 & 18:08 & $13 \mathrm{~g}$ & 04:01 \\
\hline 000016 & 8 & A101.02.01 & B004.01.03 & DR107.03.01 & $24: 13$ & 18:06 & 02:13:02 & $15: 02$ \\
\hline 000020 & 8 & A041.01.02 & B047.01.02 & DR104.10.04 & $26: 06$ & $17: 07: 01$ & $02: 16$ & 06:08 \\
\hline 000029 & 8 & A018.01.07 & B083.02.02 & DR104.08.02 & 01:09:01 & 06:01:02 & 11:01 & $16: 01$ \\
\hline 000078 & 8 & A092.02.02 & B056.04.02 & DR107.04.01 & $01: 11$ & 06:07:01 & 07:01 & $21: 02$ \\
\hline
\end{tabular}


Table 2 (continued)

\begin{tabular}{|c|c|c|c|c|c|c|c|c|}
\hline $\begin{array}{l}\text { MHC-MAFA- } \\
\text { NIAID1- }\end{array}$ & \# Obs. & Mafa-A & Mafa-B & Mafa-DRB & $\begin{array}{l}\text { Mafa- } \\
\text { DQA }\end{array}$ & $\begin{array}{l}\text { Mafa- } \\
\text { DQB }\end{array}$ & $\begin{array}{l}\text { Mafa- } \\
\text { DPA }\end{array}$ & $\begin{array}{l}\text { Mafa- } \\
\text { DPB }\end{array}$ \\
\hline 000079 & 8 & A041.01.02 & B047.01.02 & DR503.01.01 & 05:02:02 & $17: 06: 02$ & 02:14:01 & 01:05 \\
\hline 000053 & 7 & A003.01.01 & B194.01.01 & DR103.19.01 & 01:04 & 06:01:01 & 02:06:02 & 07:01 \\
\hline 000081 & 7 & A088.01.01 & B056.07.01 & DR304.09.01 & 01:03:06 & $06: 12: 02$ & 02:14:01 & 01:05 \\
\hline 000023 & 6 & A010.01.05 & В013.09.01 & DR110.03.01 & 01:24:02 & 06:13:01 & 02:13:02 & $15: 02$ \\
\hline 000044 & 6 & A067.01.03 & B090.02.02 & DR103.19.01 & 01:07:01 & $06: 14$ & $11: 01$ & $16: 01$ \\
\hline 000050 & 6 & A006.01.01 & B013.08.01 & DRW33.01.01 & $24: 04$ & $18: 05$ & $13 \mathrm{~g}$ & 04:01 \\
\hline 000067 & 6 & A067.01.01 & B048.02.01 & DR104.06.03 & 01:03:05 & $06: 12$ & 02:13:02 & $15: 02$ \\
\hline 000082 & 6 & A089.01.02 & B015.06.01 & DRW21.01.01 & $05: 10$ & 17:02:01 & 07:07 & 19:07 \\
\hline 000085 & 6 & A077.01.01 & B101.03.01 & DRW01.05.01 & $01: 13$ & $06: 17: 02$ & $02: 14: 01$ & 01:05 \\
\hline 000091 & 6 & A088.01.03 & B151.02.01 & DR103.06.02 & $01: 27$ & $06: 18$ & 13:02 & 06:06:01 \\
\hline 000033 & 5 & A097.01.02 & В002.03.01 & DRW21.01.01 & $05: 10$ & 17:02:01 & 02:15:01 & $10: 01$ \\
\hline 000034 & 5 & A010.03.01 & В056.06.03 & DRW04.01.01 & $01: 12$ & $06: 14$ & 02:09:02 & $15: 09$ \\
\hline 000049 & 5 & A053.01.01 & В015.07.01 & DR110.01.02 & $05: 16$ & $17: 11$ & 04:02 & 02:02 \\
\hline 000065 & 5 & A070.01.01 & B101.03.01 & DR110.04.01 & 05:03:01 & $16: 01$ & 13:01 & 09:02 \\
\hline 000083 & 5 & A010.01.06 & B013.08.01 & DRW01.04.02 & $01: 11$ & 06:07:01 & $02: 16$ & 06:08 \\
\hline 000086 & 5 & A024.02.01 & B104.02.04 & DRW04.01.01 & $01: 12$ & $06: 14$ & 02:15:01 & 10:01 \\
\hline 000109 & 5 & A008.01.03 & B101.03.02 & DR103.02.02 & 01:24:02 & 06:13:01 & 07:07 & 19:06:01 \\
\hline 000134 & 5 & A010.01.05 & B013.08.01 & DR103.12.01 & 01:07:01 & $06: 14$ & 07:04:01 & $20: 01$ \\
\hline 000135 & 5 & A010.01.05 & B052.02.02 & DR304.08.01 & $01: 28$ & 06:20 & $02: 51$ & 10:01 \\
\hline 000136 & 5 & A070.01.01 & В076.01.02 & DR304.09.01 & 01:03:06 & 06:12:02 & $02: 11$ & 10:01 \\
\hline 000015 & 4 & A079.01.01 & B004.01.01 & DRW01.02.02 & $24: 11$ & $18: 13$ & 04:02 & 03:04:01 \\
\hline 000040 & 4 & A067.01.02 & В012.01.01 & DR107.03.01 & $24: 13$ & $18: 06$ & 07:04:01 & $21: 01$ \\
\hline 000051 & 4 & A043.01.08 & B017.02.02 & DRW01.03.01 & $01: 11$ & 06:07:01 & $13: 03$ & 04:01 \\
\hline 000056 & 4 & A063.01.02 & В075.01.01 & DR110.04.01 & 05:03:01 & 16:01 & 13:01 & 09:02 \\
\hline 000057 & 4 & A007.01.04 & B012.01.01 & DR103.06.01 & 01:03:02 & $06: 18$ & 07:07 & 19:06:01 \\
\hline 000059 & 4 & A056.03.01 & B004.02.01 & DRW04.01.01 & $01: 12$ & $06: 14$ & 07:04:01 & 20:01 \\
\hline 000060 & 4 & A067.01.03 & B147.04.01 & DRW01.02.03 & 23:01:01 & $18: 31$ & $02: 27$ & 01:01:01 \\
\hline 000087 & 4 & A018.01.06 & B099.01.01 & DRW03.01.02 & 24:02:03 & 18:08 & $02: 26$ & $15: 06$ \\
\hline 000090 & 4 & A010.01.04 & В013.08.01 & DR103.19.01 & 01:07:01 & $06: 14$ & $13: 03$ & 04:01 \\
\hline 000098 & 4 & A004.01.02 & B090.02.01 & DRW07.01.01 & 23:01:03 & $18: 31$ & 02:15:01 & $15: 02$ \\
\hline 000102 & 4 & A004.01.02 & В056.06.02 & DRW01.04.01 & $01: 11$ & 06:07:01 & $02: 16$ & 06:08 \\
\hline 000104 & 4 & A088.01.01 & B184.01.02 & DRW04.01.01 & $01: 12$ & $06: 14$ & 02:15:01 & 10:01 \\
\hline 000107 & 4 & A043.01.06 & В028.06.02 & DR304.10.01 & $26: 15$ & $18 \mathrm{~g}$ & 07:01 & $21: 02$ \\
\hline 000115 & 4 & A033.01.03 & B045.01.03 & DR104.12.01 & 01:06:01 & $06: 11$ & $13: 03$ & 04:01 \\
\hline 000125 & 4 & A076.01.01 & В028.06.03 & DR107.02.01 & $24: 05$ & 18:05 & 04:02 & 03:04:03 \\
\hline 000128 & 4 & A004.01.02 & В056.06.03 & DR104.08.02 & 01:09:01 & 06:01:02 & $11: 01$ & $16: 01$ \\
\hline 000045 & 3 & A076.01.01 & B013.08.01 & DR104.12.01 & 01:06:01 & $06: 11$ & $02: 27$ & 01:01:01 \\
\hline 000062 & 3 & A066.01.02 & B203.01.01 & DR107.04.02 & $01: 11$ & 06:07:01 & 02:14:01 & 01:05 \\
\hline 000075 & 3 & A070.01.01 & В056.06.01 & DRW01.04 & $01 \mathrm{~g} 1$ & $06 \mathrm{~g} 3$ & $02 \mathrm{~g} 7$ & DPB-unk \\
\hline 000105 & 3 & A079.01.01 & В076.01.01 & DR103.21.01 & $24 \mathrm{~g} 1$ & 18:08 & 04:02 & $03 \mathrm{~g}$ \\
\hline 000118 & 3 & A101.01.01 & B101.04.01 & DRW21.01.01 & $05: 10$ & 17:02:01 & 07:07 & 19:07 \\
\hline 000119 & 3 & A067.01.01 & В013.10.01 & DR107.04.01 & $01: 11$ & 06:07:01 & 04:02 & 03:04:02 \\
\hline 000121 & 3 & A023.01.01 & B018.02.02 & DR103.05.01 & 05:01:01 & $17: 03$ & $02: 11$ & 10:01 \\
\hline 000126 & 3 & A088.01.01 & B045.02.03 & DRW01.04.01 & $01: 11$ & 06:07:01 & $02: 11$ & $10: 01$ \\
\hline 000012 & 2 & A066.01.05 & B083.05.01 & DRW04.03.01 & 01:03:02 & $06: 36$ & 02:15:01 & 10:01 \\
\hline 000092 & 2 & A080.01.01 & B083.02.02 & DR107.03.01 & $24: 13$ & $18: 06$ & 07:04:01 & $15: 02$ \\
\hline 000111 & 2 & A032.02.02 & B015.07.01 & DR503.01.01 & $24: 11$ & $18 \mathrm{~g} 1$ & 07:03 & $19 \mathrm{~g}$ \\
\hline 000129 & 2 & A056.03.02 & B012.01.01 & DRW01.02.03 & 23:01:01 & $18: 31$ & $02: 50$ & 01:01:01 \\
\hline
\end{tabular}


Table 2 (continued)

\begin{tabular}{|c|c|c|c|c|c|c|c|c|}
\hline $\begin{array}{l}\text { MHC-MAFA- } \\
\text { NIAID1- }\end{array}$ & \# Obs. & Mafa-A & Mafa-B & Mafa-DRB & $\begin{array}{l}\text { Mafa- } \\
\text { DQA }\end{array}$ & $\begin{array}{l}\text { Mafa- } \\
\text { DQB }\end{array}$ & $\begin{array}{l}\text { Mafa- } \\
\text { DPA }\end{array}$ & $\begin{array}{l}\text { Mafa- } \\
\text { DPB }\end{array}$ \\
\hline 000133 & 2 & A092.01.03 & B101.04.01 & DR103.20.01 & $24: 04$ & $18: 05$ & 04:02 & 03:04:01 \\
\hline 000026 & 1 & A006.01.02 & B002.04.01 & DRW21.01.01 & $05: 16$ & 17:02:01 & 07:07 & 03:06 \\
\hline 000039 & 1 & A045.01.03 & B052.01.01 & DR107.02.01 & $24: 05$ & $18: 05$ & 07:02 & 19:03 \\
\hline 000116 & 1 & A062.01.01 & B008.03.01 & DR103.01.02 & DQA-unk & 18:01:01 & 09:02 & 10:01 \\
\hline 000127 & 1 & A004.01.02 & В069.08.01 & DRW01.06.01 & 01:03:02 & $06: 20$ & DPA-unk & 04:01 \\
\hline 000137 & 1 & A004.01.02 & B083.05.02 & DRW21.02.01 & 23:01:01 & $18: 04$ & 09:02 & 17:01:02 \\
\hline 000138 & 1 & A018.01.03 & B018.02.01 & DRW33.01 & $24 \mathrm{~g} 1$ & 18:08 & $02 \mathrm{~g} 3$ & $15 \mathrm{~g} 3$ \\
\hline
\end{tabular}

2014). Likewise, another study estimated a rate of recombination in the MHC of $0.4-0.8 \%$ for the feral Mauritian population based on a statistical approach (Blancher et al. 2012). Taken together, these studies indicate that recombination events within the $5-\mathrm{Mb} \mathrm{MHC}$ region of cynomolgus macaques are relatively rare.

The availability of phased STR patterns for a significant subset of the macaques in this pedigreed breeding colony allowed us to infer MHC genotypes based on haplotype definitions listed in Table 2 and Supplemental Figures 4-6 for nearly twice as many individuals as those who were sequenced directly. In this study, we characterized the Mafa class I and class II transcripts that are associated with 100 of the most common extended MHC haplotypes that are currently segregating in this breeding colony. These 100 extended haplotypes account for $96.1 \%$ (1146 of 1192) of the total MHC haplotypes defined by STR results that are available for this breeding colony (Table 2). Distinct STR patterns have been identified for an additional 27 ancestral MHC haplotypes in this colony, but these remaining haplotypes were only detected in one to three individuals each. These rare MHC haplotypes were only detected in a total of 46 individuals and therefore only account for $3.9 \%$ of all MHC haplotypes for animals where STR data are available.

Overall the distribution of extended MHC haplotypes in this breeding colony was relatively uniform for animals whose STR patterns were known (Table 2). The extended MHC haplotype defined by the MHC-MAFA-NIAID1-000005 STR pattern was exceptional in this regard since it was observed in 120 individuals, four of whom were homozygous. The abundance of the MHC-MAFA-NIAID1-000005 haplotype reflects the fact that three of six founder males (CM94, CM9P, and CX7K) who initiated breeding in this colony between 2002 and 2005 each carried this haplotype. The available pedigree records only show that each of these founder males had different dams but their sires were unknown so they could be paternal half-siblings and at the very least must share a recent common ancestor. Together these three males sired a total of 122 progeny at Alpha Genesis for whom STR results are available and 59 of these offspring inherited the MHC-
MAFA-NIAID1-000005 haplotype. In contrast, the next most common extended MHC haplotype, MHC-MAFA-NIAID1000002 , was introduced in this colony by a single founder male (CM51). This haplotype has been observed in 62 individuals (Table 2), 25 of whom were sired by CM51. As expected, the remaining pair of founder sires $(\mathrm{CH} 2 \mathrm{D}$ and 061973) also each introduced extended MHC haplotypes (MHC-MAFA-NIAID1-000022, MHC-MAFA-NIAID1000028, MHC-MAFA-NIAID1-000132, and MHC-MAFANIAID1-000013) that are also among those most frequently observed in this colony (Table 2).

Interestingly, the most common extended MHC haplotypes described above (MHC-MAFA-NIAID1-000005 and MHCMAFA-NIAID1-000002) are both characterized by major Mafa- $B * 008$ transcripts that are closely related allelic variants. The associated Mafa-B008.02.02 and Mafa-B008.02.01 regional haplotypes are distinguished by Mafa- $B * 008: 02$ and Mafa-B*195:01 versus Mafa-B*008:03 and Mafa-B*195:02 major transcripts, respectively (Supplemental Figure 5). Fortunately, the rhesus macaque orthologue (Mamu$\left.B^{*} 008: 01\right)$ of these $M a f a-B^{*} 008$ sequences encodes one of the most thoroughly characterized MHC class I proteins in NHPs due to its strong association with exceptional control of simian immunodeficiency virus replication (Loffredo et al. 2007). Loffredo and coworkers have performed extensive epitope mapping studies and defined a detailed peptide-binding motif for the Mamu-B*008:01 protein (Loffredo et al. 2009). Since the predicted protein product of Mafa-B*008:02 only differs from its rhesus counterpart by a single V189M substitution in the alpha 2 domain that is not expected to be involved in peptide binding, it is expected to bind the same spectrum of peptides as those described for Mamu-B*008:01. The predicted Mafa-B*008:03 protein (associated with the MHC-MAFANIAID1-000002 haplotype) is also closely related to Mamu$\mathrm{B} * 008: 01$ with a conservative substitution (D101N) at a key F pocket residue in the alpha 1 domain. This asparagine variant in the Mafa-B*008:03 protein is identical to the HLA*B27:03 protein that was also shown to bind a very similar array of peptides as Mamu-B*008:01 (Loffredo et al. 2009). The Mafa-B*008:03 protein also contains a second, 
nonconservative Y140S substitution at another key F pocket residue in the alpha 2 domain relative to Mamu-B*008:01; this residue is an aspartic acid in HLA-B*27:03 (Loffredo et al. 2009). Fortuitously, the second major class I protein (Mafa-A1*007:05) of the most common MHC-MAFANIAID1-000005 haplotype also has a rhesus homolog (Mamu-A1*007:01) with a peptide-binding motif that has been determined experimentally (Reed et al. 2011). In this case, the Mafa and Mamu protein variants differ at three residues in the alpha 1 and alpha 2 domains, but two of three substitutions are highly conservative. Given the paucity of Mafa class I proteins with known peptide-binding motifs, animals that carry the two most common MHC haplotypes in this ICM colony offer a rare resource for studies that could benefit from the ability to monitor CD8 T cell responses. For example, it may be possible to use existing peptide-binding motif information to predict epitopes in a virus such as Ebola and then monitor CD8 $\mathrm{T}$ cell responses after vaccination and challenge (Sullivan et al. 2011). Moreover, since Mamu$\mathrm{B} * 008: 01$ expression is strongly associated with spontaneous control of simian immunodeficiency virus (Loffredo et al. 2009), the high frequency of Mafa-B*008:01 in these ICM could argue against their use in studies where SIV control is an important endpoint.

\section{Comparison with MHC haplotypes in other cynomolgus macaque populations}

As described above, the extended MHC haplotypes that we have characterized in this ICM breeding colony exhibit exceptional diversity. Only two of the 100 extended haplotypes listed in Table 2 appear to have been described previously. Each of the Mafa class I and class II transcripts that are associated with the MHC-MAFA-NIAID1-000056 haplotype are identical to those found on the M3 MHC haplotype of MCM (Budde et al. 2010; O'Connor et al. 2007). Likewise, the MHC-MAFA-NIAID1-000115 haplotype includes class I and class II transcripts that are all identical to the MCM M5 MHC haplotype. Comparison of the STR allele sizes for these two haplotypes with those of MCM carrying M3 or M5 haplotypes in a separate Alpha Genesis breeding colony revealed identical STR patterns (data not shown). These observations strongly suggest that these are Mauritian-origin MHC haplotypes that were inadvertently introduced to this breeding colony by founders with hybrid ancestry. A review of the pedigree records traced this pair of MCM MHC haplotypes back to two dams (CH2J and CV97) who were included among the original 2002 founders; the sires for both of these breeders are unknown. Similar observations were described for the cynomolgus macaque breeding colony at the BPRC whose founders were reported to have originated in the Indonesian islands and continental Malaysia (Otting et al. 2012). Three of the 32 extended MHC haplotypes characterized in this colony also included class I and class II transcripts that were identical to those that are associated with the M1, M3, or M4 MHC haplotypes of MCM (Otting et al. 2012; Budde et al. 2010; O'Connor et al. 2007).

The MHC-MAFA-NIAID1-000131 haplotype described here (Table 2) represents a more distant ancestral relationship to the well-characterized M1 haplotype that accounts for nearly $20 \%$ of all MHC haplotypes in the MCM population (Wiseman et al. 2013). Although nearly all of the class I transcript sequences associated with this ICM haplotype were identical with the MCM M1 haplotype, several subtle allelic variants were noted. The MHC-MAFA-NIAID1-000131 haplotype is characterized by a major Mafa-Al*063:03:02 transcript that differs from the Mafa-A1*063:01 MCM allele by three single nucleotide variants and a single G236E amino acid substitution. Likewise, a single synonymous variant distinguishes the Mafa- $B^{*}$ 104:01:02 and Mafa- $B * 104: 01: 01$ transcripts that are associated with these haplotypes. In contrast to the identical STR patterns noted between the MHCMAFA-NIAID1-000056 and MHC-MAFA-NIAID1-000115 haplotypes versus those of Mauritian-origin individuals, STR allele sizes for the MHC-MAFA-NIAID1-000131 haplotype differ from the M1 MCM haplotype at five of seven STR loci spanning the MHC class I region. In addition, the Mafa class II transcripts for each of these extended MHC haplotypes are completely unrelated. Characterization of MHC class I haplotypes of Filipino cynomolgus macaques by Shiina and coworkers (Shiina et al. 2015) revealed an even more distinct relative of MHC-MAFA-NIAID1-000131 haplotype. The B-Hp2 haplotype which represents one of the most common Mafa-B allele combinations observed in of Filipino cynomolgus macaques also shares allelic variants of five Mafa-B lineages (Mafa- $B * 104: 03$, Mafa- $B * 144: 03 N$, Mafa- $B^{*} 057: 04$, Mafa- $B^{*} 060: 02$, and Mafa-046:01:02) with the Mafa-B104.01.02 regional haplotype that comprises part of the extended MHC-MAFA-NIAID1-000131 haplotype (Supplemental Figure 5) as well as the M1 MCM haplotype (Budde et al. 2010). This Filipino B-Hp2 haplotype is also distinguished, however, by at least four completely unrelated $M a f a-B$ transcripts (Mafa- $B^{*} 050: 08$, Mafa- $B^{*} 072: 01$, Mafa$B^{*} 114: 02$, and $\left.M a f a-I^{*} 01: 12: 01\right)$ relative to its Indonesian and Mauritian counterparts (Shiina et al. 2015).

Broadly speaking, MHC haplotypes that include members of the Mafa- $B^{*} 028$ and Mafa- $B * 021$ allele lineages appear to be among the most broadly represented in cynomolgus macaques from different geographic origins as well as related macaque species. In this ICM colony, we identified six distinct variants of Mafa-B028 haplotypes that were associated with six different extended MHC haplotypes (Table 2, Supplemental Figure 5). The Mafa-B028.06.01 haplotype described here shares four identical transcripts (Mafa- $B^{*} 028: 03$, Mafa- $B^{*} 021: 01$, Mafa- $B^{*} 068: 02$, and Mafa-I*01:19) with Haplotype 23 in the BPRC cynomolgus macaque breeding 
colony (Otting et al. 2012). While five of six Mafa-B028 haplotypes in the Alpha Genesis colony include a member of the $M a f a-B^{*} 124$ lineage, the BPRC haplotype was reported to include a $M a f a-B * 144: 04$ transcript. In an earlier study of cynomolgus macaques from several Chinese breeding facilities (Karl et al. 2017), eight distinct Mafa-B028 haplotypes were characterized with different allelic variants of the Mafa$B^{*} 028$ and/or Mafa- $B^{*} 021$ lineages as well as various combinations of additional Mafa-B transcripts. Likewise, the B/IHp15 haplotype of Filipino cynomolgus macaques was reported to contain yet another combination of $M a f a-B$ allelic variants relative to these other breeding centers (Shiina et al. 2015). A variety of Mamu-B028 haplotypes have also been reported in various cohorts of Indian- and Chinese-origin rhesus macaques (Karl et al. 2013; Doxiadis et al. 2013). In addition, PacBio sequencing analyses identified at least three distinct Mane-B028 haplotypes in several pig-tailed macaque cohorts (Semler et al. 2018). Taken together, these observations suggest that the primordial combination of $B^{*} 028$ and $B^{*} 021$ genes was likely to have arisen in a common ancestor who predated the divergence of cynomolgus, rhesus and pigtailed macaques (Smith et al. 2007).

\section{Concluding remarks}

Here, we describe a comprehensive, high-resolution characterization of the Mafa class I and class II transcripts that are associated with 100 extended MHC haplotypes in a large, pedigreed colony of ICM. PacBio sequencing of this cohort yielded 202 new Mafa transcript sequences with full-length coding regions, bringing the number in IPD-MHC Release 3.3.0.0 (2019-06-13) build 126 to a total of 2489 Mafa sequences. This study was informed by an extensive database of STR patterns for a panel of markers that span the $5-\mathrm{Mb}$ MHC genomic region that has been collected since this breeding colony was established in 2002. The STR data allowed us to define the allele content of extended MHC haplotypes for individuals that were known to share chromosomes that were identical by descent rather than simply inferring haplotypes based on combinations of class I and class II transcripts that appear to travel together in multiple animals who lack known pedigree relationships. A large majority of the 70 Mafa-A, 78 Mafa-B, and 45 Mafa-DRB haplotypes identified here were only associated with one or two of the 100 extended MHC haplotypes that we characterized. This extensive MHC diversity was derived from only approximately 79 founding animals for this breeding colony. In contrast, a comparable study of Indian-origin rhesus only identified 17 Mamu-A, 18 Mamu-B, and 22 Mamu-DRB haplotypes in the BPRC breeding colony that was established with 137 founding animals (Doxiadis et al. 2013).
Although this dataset is restricted to a single ICM breeding colony, it provides a glimpse of extraordinary MHC diversity that must be present in the wild population of ICM as a whole. It is reasonable to predict that the high level of genetic diversity described here for the MHC region will extend across the rest of the ICM genome. As previously noted, MCM are thought to be derived from a founder population of ICM (Lawler et al. 1995; Tosi and Coke 2007) which significantly limited the genomic diversity in MCM, especially in the MHC region where only seven ancestral haplotypes are observed. While this restricted genetic diversity is valuable in many areas of research, it can present a challenge for transplant investigators whose goal is to maximize MHC disparity between donor and recipient tissues. The ICM population, in contrast, exhibits considerably more diversity, increasing its value as a model species for biomedical research, such as transplantation studies. This pedigreed cynomolgus macaque cohort also provides a valuable resource for future studies designed to characterize additional immune-important genomic regions such as the killer immunoglobulin-like receptors (Bimber and Evans 2015; Prall et al. 2017; Bruijnesteijn et al. 2018) and Fc gamma receptors (Haj et al. 2019).

Acknowledgments We appreciate pedigree information provided by Isabelle Lussier for the Alpha Genesis ICM breeding colony. We also thank the University of Wisconsin Biotechnology Center DNA Sequencing Facility for providing Pacific Biosciences library preparation and sequencing services. In addition, we are extremely grateful for the expert assistance of Nel Otting and Natasja de Groot in providing official IPD-MHC allele nomenclature for the novel sequences and extensions of partial sequences that are reported here. This work was made possible by financial support through contract HHSN272201600007C from the National Institute of Allergy and Infectious Diseases of the NIH. This work was also supported in part by the Office of Research Infrastructure Programs/ OD (P51OD011106) awarded to the Wisconsin National Primate Research Center at the University of Wisconsin-Madison. This research was conducted in part at a facility constructed with support from Research Facilities Improvement Program grants RR15459-01 and RR020141-01.

\section{Compliance with ethical standards}

The authors declare that they have no conflicts of interest.

Ethical approval All applicable international, national, and/or institutional guidelines for the care and use of animals were followed.

\section{References}

Aarnink A, Mee ET, Savy N, Congy-Jolivet N, Rose NJ, Blancher A (2014) Deleterious impact of feto-maternal MHC compatibility on the success of pregnancy in a macaque model. Immunogenetics 66(2):105-113

Bimber BN, Evans DT (2015) The killer-cell immunoglobulin-like receptors of macaques. Immunol Rev 267(1):246-258

Blancher A, Aarnink A, Savy N, Takahata N (2012) Use of cumulative Poisson probability distribution as an estimator of the recombination 
rate in an expanding population: example of the Macaca fascicularis major histocompatibility complex. G3 (Bethesda) 2(1):123-130

Bruijnesteijn J, van der Wiel MKH, Swelsen WTN, Otting N, de VosRouweler AJM, Elferink D, Doxiadis GG, Claas FHJ, Lardy NM, de Groot NG, Bontrop RE (2018) Human and rhesus macaque KIR haplotypes defined by their transcriptomes. J Immunol 200(5): $1692-1701$

Budde ML, Wiseman RW, Karl JA, Hanczaruk B, Simen BB, O'Connor DH (2010) Characterization of Mauritian cynomolgus macaque major histocompatibility complex class I haplotypes by high-resolution pyrosequencing. Immunogenetics 62(11-12):773-780

Burwitz BJ, Wu HL, Abdulhaqq S, Shriver-Munsch C, Swanson T, Legasse AW, Hammond KB, Junell SL, Reed JS, Bimber BN, Greene JM, Webb GM, Northrup M, Laub W, Kievit P, MacAllister R, Axthelm MK, Ducore R, Lewis A, Colgin LMA, Hobbs T, Martin LD, Ferguson B, Thomas CR, PanoskaltsisMortari A, Meyers G, Stanton JJ, Maziarz RT, Sacha JB (2017) Allogeneic stem cell transplantation in fully MHC-matched Mauritian cynomolgus macaques recapitulates diverse human clinical outcomes. Nat Commun 8(1):1418

Caskey JR, Wiseman RW, Karl JA, Baker DA, Lee T, Maddox RJ, Raveendra M, Harris RA, Hu K, Munzy DM, Rogers J, O'Connor DH (2019) MHC genotyping from rhesus macaque exome sequences. Immunogenetics 71:531-544

Creager HM, Becker EA, Sandman KK, Karl JA, Lank SM, Bimber BN, Wiseman RW, Hughes AL, O'Connor SL, O'Connor DH (2011) Characterization of full-length MHC class II sequences in Indonesian and Vietnamese cynomolgus macaques. Immunogenetics 63(9):611-618

Daza-Vamenta R, Glusman G, Rowen L, Guthrie B, Geraghty DE (2004) Genetic divergence of the rhesus macaque major histocompatibility complex. Genome Res 14:1501-1515

de Groot NG, Otting N, Maccari G, Robinson J, Hammond JA, Blancher A, Lafont BAP, Guethlein LA, Wroblewski EE, Marsh SGE, Shiina T, Walter L, Vigilant L, Parham P, O’Connor DH, Bontrop RE (2019) Nomenclature report 2019: major histocompatibility complex genes and alleles of Great and Small Ape and Old and New World monkey species. Immunogenetics 72(1-2):25-36

Doxiadis GG, de Groot N, Otting N, de Vos-Rouweler AJ, Bolijn MJ, Heijmans CM, de Groot NG, van der Wiel MK, Remarque EJ, Vangenot C, Nunes JM, Sanchez-Mazas A, Bontrop RE (2013) Haplotype diversity generated by ancient recombination-like events in the MHC of Indian rhesus macaques. Immunogenetics 65(8): $569-584$

Ezzelarab MB, Zhang H, Guo H, Lu L, Zahorchak AF, Wiseman RW, Nalesnik MA, Bhama JK, Cooper DK, Thomson AW (2016) Regulatory $\mathrm{T}$ cell infusion can enhance memory $\mathrm{T}$ cell and alloantibody responses in Lymphodepleted nonhuman primate heart allograft recipients. Am J Transplant 16(7):1999-2015

Fichot E, Norman R (2013) Microbial phylogenetic profiling with the Pacific Biosciences sequencing platform. Microbiome 1:10. https://doi.org/10.1186/2049-2618-1-10

Fukami-Kobayashi K, Shiina T, Anzai T, Sano K, Yamazaki M, Inoko H, Tateno Y (2005) Genomic evolution of MHC class I region in primates. Proc Natl Acad Sci U S A 102(26):9230-9234

Haj AK, Arbanas JM, Yamniuk AP, Karl JA, Bussan HE, Drinkwater KY, Graham ME, Ericsen AJ, Prall TM, Moore K, Cheng L, Gao M, Graziano RF, Loffredo JT, Wiseman RW, O'Connor DH (2019) Characterization of Mauritian cynomolgus macaque $\mathrm{Fc} \gamma \mathrm{R}$ alleles using long-read sequencing. J Immunol 202(1):151-159

Heimbruch KE, Karl JA, Wiseman RW, Dudley DM, Johnson Z, Kaur A, O'Connor DH (2015) Novel MHC class I full-length allele and haplotype characterization in sooty mangabeys. Immunogenetics 67(8):437-445

Karl JA, Bohn PS, Wiseman RW, Nimityongskul FA, Lank SM, Starrett GJ, O’Connor DH (2013) Major histocompatibility complex class I haplotype diversity in Chinese rhesus macaques. G3 (Bethesda) 3(7):1195-1201

Karl JA, Heimbruch KE, Vriezen CE, Mironczuk CJ, Dudley DM, Wiseman RW, O'Connor DH (2014) Survey of major histocompatibility complex class II diversity in pig-tailed macaques. Immunogenetics 66(11):613-623

Karl JA, Graham ME, Wiseman RW, Heimbruch KE, Gieger SM, Doxiadis GG, Bontrop RE, O'Connor DH (2017) Major histocompatibility complex haplotyping and long-amplicon allele discovery in cynomolgus macaques from Chinese breeding facilities. Immunogenetics 69:211-229

Kato Y, Griesemer AD, Wu A, Sondermeijer HP, Weiner JI, DuranStruuck R, Martinez M, Slate AR, Romanov A, Lefkowitch JH, Sykes M, Kato T (2017) Novel H-shunt Venovenous bypass for liver transplantation in Cynomolgus macaques. Comp Med 67:436-441

Kean LS, Singh K, Blazar BR, Larsen CP (2012) Nonhuman primate transplant models finally evolve: detailed immunogenetic analysis creates new models and strengthens the old. Am J Transplant 12(4): 812-819

Kita YF, Hosomichi K, Kohara S, Itoh Y, Ogasawara K, Tsuchiya H, Torii R, Inoko H, Blancher A, Kulski JK, Shiina T (2009) MHC class I A loci polymorphism and diversity in three Southeast Asian populations of cynomolgus macaque. Immunogenetics 61:635-648

Knechtle SJ, Shaw JM, Hering BJ, Kraemer K, Madsen JC (2019) Translational impact of NIH-funded nonhuman primate research in transplantation. Sci Transl Med 11(500)

Larsen CP, Page A, Linzie KH, Russell M, Deane T, Stempora L, Strobert E, Penedo MC, Ward T, Wiseman R, O'Connor D, Miller W, Sen S, Singh K, Kean LS (2010) An MHC-defined primate model reveals significant rejection of bone marrow after mixed chimerism induction despite full MHC matching. Am J Transplant 10(11):23962409

Lawler SH, Sussman RW, Taylor LL (1995) Mitochondrial DNA of the Mauritian macaques (Macaca fascicularis): an example of the founder effect. Am J Phys Anthropol 96:133-141

Loffredo JT, Maxwell J, Qi Y, Glidden CE, Borchardt GJ, Soma T, Bean AT, Beal DR, Wilson NA, Rehrauer WM, Lifson JD, Carrington M, Watkins DI (2007) Mamu-B*08-positive macaques control simian immunodeficiency virus replication. J Virol 81(16):8827-8832

Loffredo JT, Sidney J, Bean AT, Beal DR, Bardet W, Wahl A, Hawkins OE, Piaskowski S, Wilson NA, Hildebrand WH, Watkins DI, Sette A (2009) Two MHC class I molecules associated with elite control of immunodeficiency virus replication, Mamu-B*08 and HLA$\mathrm{B} * 2705$, bind peptides with sequence similarity. J Immunol 182(12):7763-7775

Maccari G, Robinson J, Ballingall K, Guethlein LA, Grimholt U, Kaufman J, Ho CS, de Groot NG, Flicek P, Bontrop RE, Hammond JA, Marsh SG (2017) IPD-MHC 2.0: an improved inter-species database for the study of the major histocompatibility complex. Nucleic Acids Res 45(D1):D860-D864

Matsunami M, Rosales IA, Adam BA, Oura T, Mengel M, Smith RN, Lee H, Cosimi AB, Colvin RB, Kawai T (2019) Long-term kinetics of intragraft gene signatures in renal allograft tolerance induced by transient mixed chimerism. Transplantation 103:e334-e344

Morizane A, Kikuchi T, Hayashi T, Mizuma H, Takara S, Doi H, Mawatari A, Glasser MF, Shiina T, Ishigaki H, Itoh Y, Okita K, Yamasaki E, Doi D, Onoe H, Ogasawara K, Yamanaka S, Takahashi J (2017) MHC matching improves engraftment of iPSC-derived neurons in non-human primates. Nat Commun 8(1): 385

O'Connor SL, Blasky AJ, Pendley CJ, Becker EA, Wiseman RW, Karl JA, Hughes AL, O'Connor DH (2007) Comprehensive characterization of MHC class II haplotypes in Mauritian cynomolgus macaques. Immunogenetics 59(6):449-462

Otting N, de Groot N, de Vos-Rouweler AJ, Louwerse A, Doxiadis GG, Bontrop RE (2012) Multilocus definition of MHC haplotypes in 
pedigreed cynomolgus macaques (Macaca fascicularis). Immunogenetics 64(10):755-765

Otting N, van der Wiel MK, de Groot N, de Vos-Rouweler AJ, de Groot NG, Doxiadis GG, Wiseman RW, O'Connor DH, Bontrop RE (2017) The orthologs of HLA-DQ and -DP genes display abundant levels of variability in macaque species. Immunogenetics 69(2):8799

Pendley CJ, Becker EA, Karl JA, Blasky AJ, Wiseman RW, Hughes AL, O'Connor SL, O'Connor DH (2008) MHC class I characterization of Indonesian cynomolgus macaques. Immunogenetics 60:339-351

Penedo MC, Bontrop RE, Heijmans CM, Otting N, Noort R, Rouweler AJ, de Groot N, de Groot NG, Ward T, Doxiadis GG (2005) Microsatellite typing of the rhesus macaque MHC region. Immunogenetics 57:198-209

Prall TM, Graham ME, Karl JA, Wiseman RW, Ericsen AJ, Raveendran M, Alan Harris R, Muzny DM, Gibbs RA, Rogers J, O'Connor DH (2017) Improved full-length killer cell immunoglobulin-like receptor transcript discovery in Mauritian cynomolgus macaques. Immunogenetics 69(5):325-339

Reed JS, Sidney J, Piaskowski SM, Glidden CE, León EJ, Burwitz BJ, Kolar HL, Eernisse CM, Furlott JR, Maness NJ, Walsh AD, Rudersdorf RA, Bardet W, McMurtrey CP, O'Connor DH, Hildebrand WH, Sette A, Watkins DI, Wilson NA (2011) The role of MHC class I allele Mamu-A*07 during SIV(mac)239 infection. Immunogenetics 63(12):789-807

Semler MR, Wiseman RW, Karl JA, Graham ME, Gieger SM, O'Connor DH (2018) Novel full-length major histocompatibility complex class I allele discovery and haplotype definition in pig-tailed macaques. Immunogenetics 70(6):381-399

Shiina T, Blancher A (2019) The Cynomolgus macaque MHC polymorphism in experimental medicine. Cells 8(9):978

Shiina T, Yamada Y, Aarnink A, Suzuki S, Masuya A, Ito S, Ido D, Yamanaka $\mathrm{H}$, Iwatani $\mathrm{C}$, Tsuchiya $\mathrm{H}$, Ishigaki $\mathrm{H}$, Itoh $\mathrm{Y}$, Ogasawara K, Kulski JK, Blancher A (2015) Discovery of novel MHC-class I alleles and haplotypes in Filipino cynomolgus macaques (Macaca fascicularis) by pyrosequencing and Sanger sequencing: Mafa-class I polymorphism. Immunogenetics 67(10): $563-578$
Shiina T, Blancher A, Inoko H, Kulski JK (2017) Comparative genomics of the human, macaque and mouse major histocompatibility complex. Immunology 150:127-138

Smith DG, McDonough JW, George DA (2007) Mitochondrial DNA variation within and among regional populations of longtail macaques (Macaca fascicularis) in relation to other species of the fascicularis group of macaques. Am J Primatol 69(2):182-198

Sullivan NJ, Hensley L, Asiedu C, Geisbert TW, Stanley D, Johnson J, Honko A, Olinger G, Bailey M, Geisbert JB, Reimann KA, Bao S, Rao S, Roederer M, Jahrling PB, Koup RA, Nabel GJ (2011) CD8+ cellular immunity mediates rAd5 vaccine protection against Ebola virus infection of nonhuman primates. Nat Med 17(9):1128-1131

Tosi AJ, Coke CS (2007) Comparative phylogenetics offer new insights into the biogeographic history of Macaca fascicularis and the origin of the Mauritian macaques. Mol Phylogenet Evol 42:498-504

Watanabe A, Shiina T, Shimizu S, Hosomichi K, Yanagiya K, Kita YF, Kimura T, Soeda E, Torii R, Ogasawara K, Kulski JK, Inoko H (2007) A BAC-based contig map of the cynomolgus macaque (Macaca fascicularis) major histocompatibility complex genomic region. Genomics 89(3):402-412

Westbrook CJ, Karl JA, Wiseman RW, Mate S, Koroleva G, Garcia K, Sanchez-Lockhart M, O'Connor DH, Palacios G (2015) No assembly required: full-length $\mathrm{MHC}$ class I allele discovery by PacBio circular consensus sequencing. Hum Immunol 76(12):891-896

Wiseman RW, Karl JA, Bohn PS, Nimityongskul FA, Starrett GJ, O'Connor DH (2013) Haplessly hoping: macaque major histocompatibility complex made easy. ILAR J 54(2):196-210

Zhang H, Guo H, Lu L, Zahorchak AF, Wiseman RW, Raimondi G, Cooper DK, Ezzelarab MB, Thomson AW (2015) Sequential monitoring and stability of ex vivo-expanded autologous and nonautologous regulatory $\mathrm{T}$ cells following infusion in nonhuman primates. Am J Transplant 15(5):1253-1266

Publisher's note Springer Nature remains neutral with regard to jurisdictional claims in published maps and institutional affiliations. 